\title{
A CONTENT ANALYSIS OF FOUR EXPLANATORY MODELS OF THE MORAL DEVELOPMENT
}

\author{
Ştefania BUMBUC \\ “Nicolae Bălcescu” Land Forces Academy, Sibiu, Romania \\ stefanabumbuc@gmail.com
}

\begin{abstract}
Numerous studies have focused on identifying the stages of ethical decision process and the factors that can influence it, aiming to provide tools for educators' struggle of improving the moral profile of the students. The purpose of this paper is to present an overview of the four explanatory theoretical models of moral development, in order to notice the relationship between the rational and the emotional components of personality during the moral decision-making process and to highlight their impact on educational process. It is resumed a qualitative research that was developed using the Atlas.ti software. The results sustain the empirical observation that educators change the focus of the moral explanation, moral story and moral conversation towards the more interactive methods, like moral case study and moral exercise.
\end{abstract}

\section{Keywords: moral development, moral education, theoretical models}

\section{Introduction}

Whereas the purpose of the moral education is to develop individuals ability to recognize and promptly respond when facing a moral dilemma, the development of certain skills for resolving moral dilemmas can be achieved through a number of actions that involve examination of different philosophical approaches of ethics, evaluation of some decisions and consequences of historical moral issues, discussing the current moral dilemmas that faced various persons etc.

Numerous studies have focused on identifying the stages of ethical decision process and the factors that influence it, aiming to provide tools that educators, leaders, institutions or communities can use them successfully in solving ethical issues they face. Modern studies are based on the contribution of renowned researchers and theorists, whose theories and models remain fundamental references in the field. For example, Jean Piaget's research led to the elaboration of Lawrence Kohlberg's theory of moral development, theory which was subsequently followed by the majority of explanatory models of the process of moral decision.

\section{Aim}

We will present an overview of the four explanatory theoretical models offered by literature on formation and development of moral profiles of individuals, in order to highlight their impact on educators and educational process. The purpose is to notice the relationship between the rational and the emotional components of personality during the evolution of theories.

\section{Theoretical frame}

One of the most known theories in the field was elaborated in 1981 by Lawrence Kohlberg [1]. Since then the theory was progressively enriched and 
completed with a lot of studies. Lawrence Kohlberg's moral development theory is a milestone because offered to scholars, practitioners, psychologists or teachers the opportunity of diversifying their views and deeper understanding of certain individual and social phenomena. In the same time, this theory enabled the emergence of scientific disagreements. Based on this theory, the foundation of many educational programs in schools worldwide was possible and also the diversification of specific teaching methodology for moral formation of the young.

Kohlberg's theory is a stage theory, based on Jean Piaget's previous studies on child stages of moral reasoning development. These six stages of moral development are considered to be the results of individual thought on moral issues, and they are mentioned in numerous studies in the field:

a) The morality of obedience - Do what you are told!

b) The morality of instrumental egoism and simple exchange - Let's make a deal!

c) The morality of interpersonal concordance - Be considerate, nice and kind, so you'll make friends!

d) The morality of law and social orderEverybody in society is obligated to and protected by the law!

e) The morality of consensus building procedure - You are obligated by the arrangements that are agreed to by due process procedures!

f) The morality of nonarbitrary social cooperation - Morality is defined by how rational and impartial people would ideally organize cooperation.

A few years later, in 1986, having as a starting point the Kohlberg's theory, James R. Rest [2] published an analysis from another perspective of the components of decision making process in ethical circumstances, developing the ethical decision-making model. Later, along with various collaborators, including Darcia Narvaez [3], he developed some psychological instruments for measuring the components of ethical decision, but at the same time he investigated the educational implications of these phenomena. According to the theoretical model mentioned before, an ethical decision is composed of four distinct psychological processes:

a) Moral sensitivity (moral consciousness) refers to a person's ability to recognize that the situation facing contains a moral issue. When interpreting a situation morally problematic, a person must respond primarily to three questions: What are the possible courses of action? Who will be affected by each course of action? How the parties involved will consider these effects on their sense of well and their interests?

It should be noted that many people have difficulties in interpreting the significance of relatively simple situations. Often, these difficulties are underestimated and the misunderstanding should not always be considered as a conscious defensive mechanism. Also, differences in moral sensitivity between individuals may be remarkable, especially in terms of assessing the welfare and others needs. Sometimes violence can reach before people understand that is about a moral issue; in other cases, people are so sensitive that any action (such as a simple grimace) has moral implications. A social situation can arouse emotions before it wake up cognitive activity which involves judging the facts. The recognition of a moral issue involves the recognition that owns actions have the potential to injure somebody or bring benefit to someone else. Scott Reynolds broadens the meaning of the moral sensitivity concept, considering that it includes also the fact that if a person considers that a situation has moral content, then a moral decision in that case is justified and valid.

b) Moral judgment relates to the formulation and evaluation of moral justification for possible solutions identified. At this stage it is necessary the 
reasoning about the possible choices and their potential consequences, in order to make the most correct choice from ethical perspective.

c) Moral motivation (moral intention) refers to the intention to make a moral choice at the expense of another solution which represents another value. This part of the decision-making process requires commitment to a moral value. For example, an individual must choose between two possible solutions: one brings a number of benefits (for example, it increases its power) and the other is morally correct. In this case, moral motivation is the intention of the individual to choose moral value to the detriment of power value.

d) Moral courage (moral action) refers to the engagement in moral behavior in the specific circumstances. Courage, determination and ability to carry through moral decision are required. This supposed to determine the sequence of concrete action, to overcome unexpected obstacles and difficulties, to resist to distractions and temptations, and to keep personal goals. Assertiveness, perseverance, competence, firmness of character are attributes that lead to success, and positive emotional state and focus on success will determine the amount of effort which will be submitted and the quantity of resistance to adversity.

J. R. Rest considered that these four sequences are distinct, but is not necessary that the process be carried out in this order. Failure in any of these components results in the failure of the entire ethical decision process. An individual may have a solid moral judgment, but it may be useless if it lacks the moral sensibilities and fails to recognize a moral issue. If there is an overlap between two moral problems, the concern for one of them can cause moral insensitivity for the other. As the cost of a moral action is realized, a person can distort their obligation feelings, can deny personal responsibility or reassess the situation so as to choose suitable alternative. As people realize the implications of judgment and motivation, they can reassess the interpretation of the situation in the defensive way, so as to continue to feel honorable and still win in the case.

Another theory that we will analyze is the model of moral intensity, which belongs to Thomas Jones [4]. The author introduces the concept of moral intensity with reference to all the characteristics of the moral issues that affect individual decisions. In the proposed model, the moral intensity influences all four components of the J. R. Rest model.

According to T. Jones, there are six dimensions of moral issues which determine the moral intensity:

a) Magnitude of consequences: is the sum of the harms (or benefits) done to victims (or beneficiaries) of the moral act in question; the higher the possibility of being hurt or benefit, the greater moral intensity.

b) Social consensus: refers to the degree of conformity within a social group on the negative or positive value of an action; a small group of people or society as a whole can be considered a social group; a high social consensus increases the moral intensity of an act considered to be morally wrong.

c) Probability of effect: the probability that the act in question will actually take place and the act in question will actually cause the harm (benefit) predicted. If the probability of taking place and the possible damages are high, then moral intensity increases.

d) Temporal immediacy: is the length of time between the present and the onset of consequences of the moral act in question (shorter length of time implies greater immediacy). An action that has immediate negative consequences will cause a higher moral intensity compared to an action whose consequences are distant.

e) Proximity: is the feeling of nearness (social, cultural, psychological, or physical) that the moral agent has for victims (beneficiaries) of the evil (beneficial) action 
in question. An increase in proximity leads to an increase in moral intensity.

f) Concentration of effect: refers to the relationship between the number of people affected and the magnitude of the evil; if the concentration effect is great, moral intensity increases.

The fourth of the explanatory models covered by this paper is the social intuitionist model and belongs to Jonathan Haidt [5]. According to his psychological and sociological research the author concludes that most of our everyday moral judgments and moral behavior are intuitive, being present in our consciousness without knowing how they got there. Jonathan Haidt goes further the construction of the intuitionist model of moral conduct stating that the moral reasoning is an act of thought, of passing through the filter of reason, which happens subsequently the intuitive manifestation of our behavior. The researcher offers four reasons why his model of moral conduct is an accurate one. First, our behavior is driven simultaneously by two types of mental processes: conscious and unconscious. Secondly, people's thinking is acting more like a defense attorney than as an impartial judge, seeking constantly to defend moral actions. Thirdly, people often cannot explain why they do the things they do; therefore everyone invents

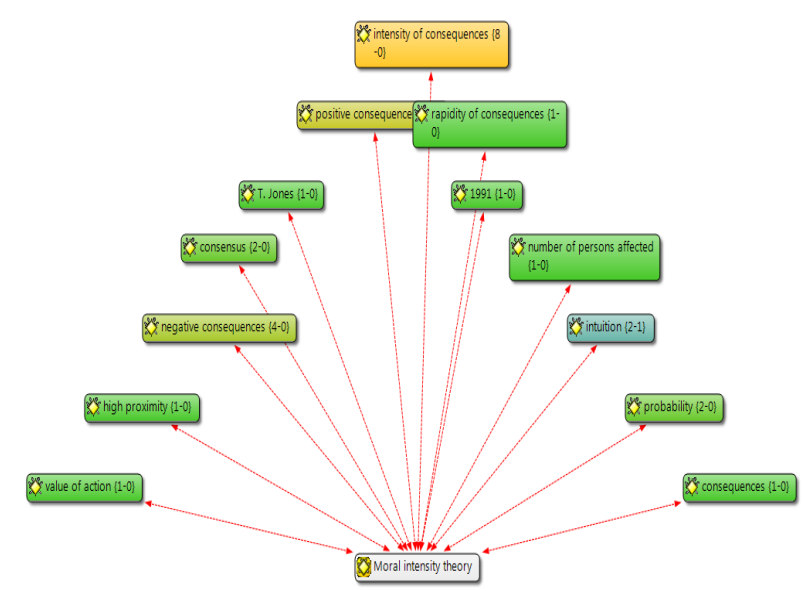

Figure 1: Components of moral intensity theory

It can be seen the presence, in approximately the same extent (suggested by the same yellow and olive-green colors post-action a number of reasons, particularly when they are under pressure to provide explanations and answers. Fourth, the author cites several studies indicating that moral actions are influenced by emotions to a greater extent than by moral reasoning. The model says that most of the action in moral psychology is in the intuitions and is an automatic evaluative response.

\section{Methods}

We developed a qualitative research on these four theories and explanatory models using the Atlas.ti software. Following the completion of the content analysis, we first made the semantically encoding of the theories' components. The resulted codes were processed, and then were used the co-occurrence tools to identify the significance and to emphasize the relationships between the main psychological concepts involved.

\section{Results and discussions}

During the first step of the content analysis of Jones and Rest theories, named the semantically encoding, were resulted 32 codes, which were organized in two graphical representations of the basic concepts that make up the two explanatory models:

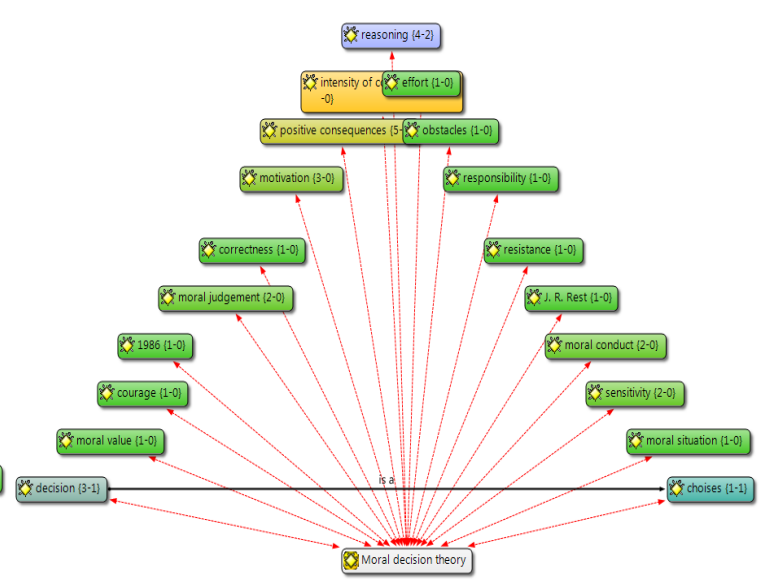

Figure 2: Components of moral decision theory

that chart used) of the following concepts: intensity of consequences and positive consequences, as pillars of the two 
theoretical models analyzed. These evidences have behaviorist bases, being consistent with the Thorndike's theory and especially with the Skinner's theory of operant conditioning.

By semantically encoding of all four explanatory models of moral development, followed by data

\begin{tabular}{|c|c|c|c|c|c|c|c|c|c|}
\hline CODES & choices & decision & $\begin{array}{l}\text { intensity of } \\
\text { consequences }\end{array}$ & $\begin{array}{c}\text { negative } \\
\text { consequencess }\end{array}$ & $\begin{array}{c}\text { positive } \\
\text { consequences }\end{array}$ & probability 1 & reasoning & sensitivity & TOTAL \\
\hline consensus & 0 & 0 & 0,11 & 0 & 0 & 0 & 0 & 0 & 0,11 \\
\hline consequences & 0 & 0 & 0,13 & 0 & 0 & 0 & 0 & 0 & 0,13 \\
\hline decision & 0 & 0 & 0,1 & 0 & 0,14 & 0 & 0,17 & 0,25 & 0,66 \\
\hline $\begin{array}{l}\text { intensity of } \\
\text { consequences }\end{array}$ & 0,13 & 0,1 & 0 & 0,5 & 0,44 & 0,25 & 0,09 & 0 & 1,51 \\
\hline intuition & 0 & 0 & 0 & 0 & 0 & 0 & 0,5 & 0,33 & 0,83 \\
\hline $\begin{array}{l}\text { moral } \\
\text { conduct }\end{array}$ & 0 & 0 & 0 & 0 & 0 & 0 & 0,2 & 0 & 0,2 \\
\hline $\begin{array}{c}\text { moral } \\
\text { judgment }\end{array}$ & 0 & 0,25 & 0 & 0 & 0,17 & 0 & 0,2 & 0 & 0,62 \\
\hline motivation & 0,33 & 0,2 & 0,22 & 0 & 0 & 0 & 0,4 & 0,25 & 1,41 \\
\hline $\begin{array}{c}\text { negative } \\
\text { consequences }\end{array}$ & 0 & 0 & 0,5 & 0 & 0,8 & 0,5 & 0 & 0 & 1,8 \\
\hline $\begin{array}{c}\text { positive } \\
\text { consequences }\end{array}$ & 0 & 0,14 & 0,44 & 0,8 & 0 & 0,4 & 0 & 0 & 1,79 \\
\hline probability & 0 & 0 & 0,25 & 0,5 & 0,4 & 0 & 0 & 0 & 1,15 \\
\hline reasoning & 0,25 & 0,17 & 0,09 & 0 & 0 & 0 & 0 & 0,5 & 1,01 \\
\hline sensitivity & 0 & 0,25 & 0 & 0 & 0 & 0 & 0,5 & 0 & 0,75 \\
\hline
\end{tabular}

It can be seen that the highest scores were achieved by concepts intensity of consequences, positive consequences and negative consequences. The relationships processing using the content analysis Atlas.ti software, were identified the significant co-occurrences of the codes entered. The table below shows the situation of co-occurrences of the highest frequency codes from the four theories.

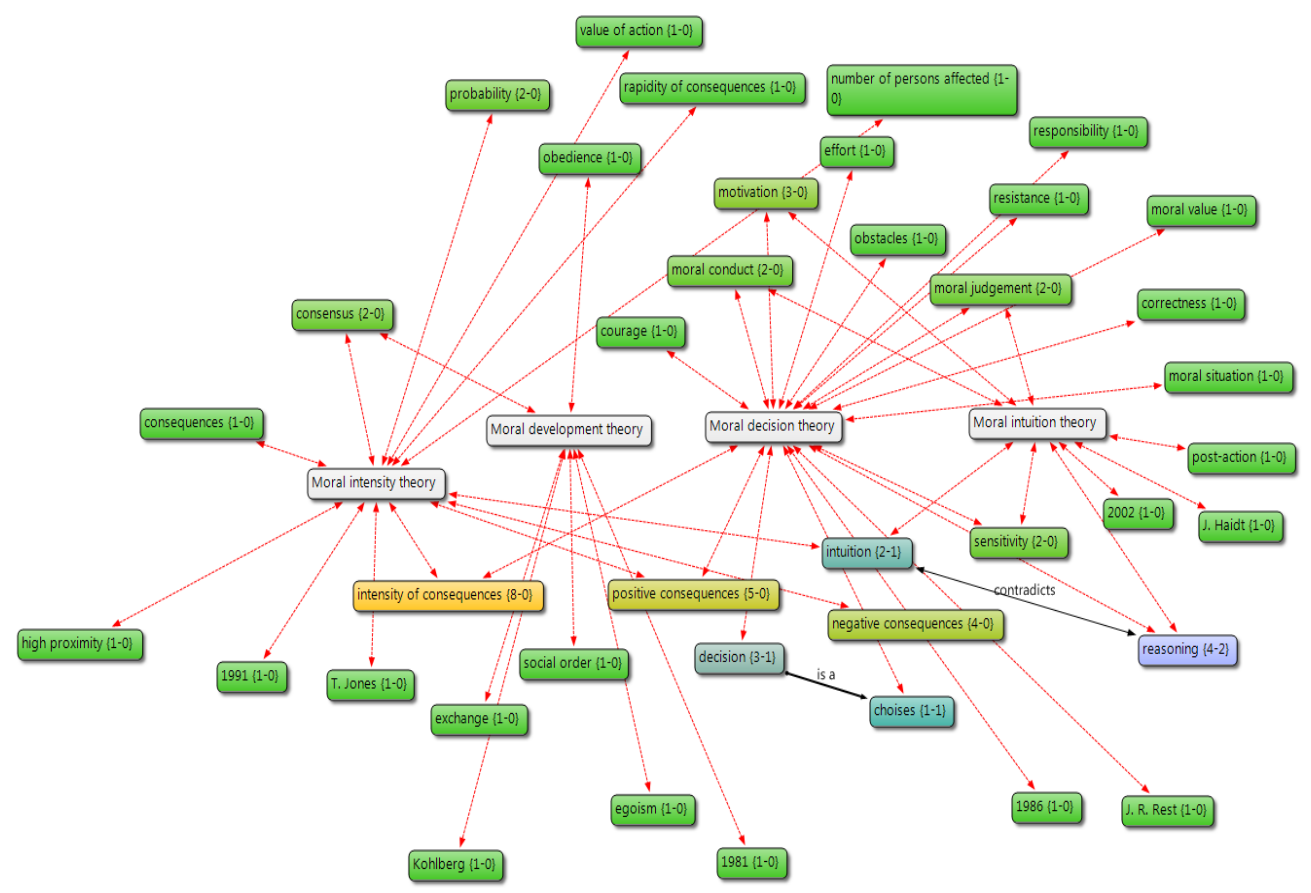

Figure 3: The network of codes 
A significant co-occurrence $(\geq 0.5)$ can be also seen at the pair of codes reasoning and intuition, as well as the pair of codes reasoning and sensitivity. The constant association between the rational and the emotional side of personality in the case of ethical decisions emphasizes the need of designing the pedagogical interventions in two ways: comprehension, explanation and argumentation, on the one hand, and emotion, experience and feeling, on the other hand. Verbal teaching methods should always be combined with slideshow, case studies or moral problematization. Similarly, in the classroom, any image, didactic video or story of some moral events must be followed by explanations and enlightening conversations conducted by teachers. These are part of the basic principles of moral education, no matter of the age of the subjects.

An idea that stands out refers to the gradual transition of explanatory models from focusing on the rational analysis of situations, on moral judgment and awareness of the consequences of the decision, to focus on intuitive and probabilistic action, based on sensitivity and followed by of post-action judgment. Certain effects of this theoretical trend may be identified at the level of educational methods at various ages of the subjects. Educators change the focus of the moral explanation, moral story and moral conversation towards the active methods, like case study and moral exercise. These latter are carried out in modern education through virtual simulations of some typical and representative moral situations.

\section{Conclusion}

The consequences of the moral actions remain in the spotlight of theorists and practitioners, specialists of moral education. What is changed in time concerning the explanatory models of moral decisions of individuals is only the specific moment when it is considered that moral judgment comes into action: before or after those events took place. The theoretical and methodological option of educators shapes different teaching strategies, whose effectiveness could be established later, by running longitudinal researches.

\section{References}

[1] L. Kohlberg, Essays on Moral Development, vol. I and II, Harper \& Row Publishing House, 1981, 1984.

[2] J. R. Rest, Moral Development: Advances in research and theory, New York: Praeger Publishing House, 1986.

[3] J. R. Rest, D. Narvaez, Moral development in the professions: Psychology and applied ethics, New Jersey: Lawrence Erlbaum Associates, 1994.

[4] T. Jones, "Ethical decision making by individuals in organizations: An issue-contingent model", Academy of Management Review, 2 (16)/1991, pp.366-395.

[5] J. Haidt, „The emotional dog and its rational tail: A social intuitionist approach to moral judgment", Psychological Review, 108(4)/2001, pp.814-834. 